\title{
Innovative Opportunities for Insurance Development in a New Financial Paradigm
}

\author{
Mano Mgeryan ${ }^{1, *}$, Gilyan Fedotova ${ }^{2}$, Vyacheslav Borulko ${ }^{3}$, Alexandr Kulakov ${ }^{4}$, and Yuliya \\ Kapustina ${ }^{5}$ \\ ${ }^{1}$ Ural state University of Economics, 620144 Ekaterinburg, Russia \\ ${ }^{2}$ Volga region research Institute of production and processing of meat and dairy products, 400131 \\ Volgograd, Russia \\ ${ }^{3}$ Russian state agrarian University named after K.A. Timiryazev, 127434 Moscow, Russia \\ ${ }^{4}$ University College London, London, United Kingdom \\ ${ }^{5}$ Ural State Forestry University, 620100 Yekaterinburg, Russia
}

\begin{abstract}
This article examines and analyses innovative opportunities for insurance development in Russia. Thanks to innovative opportunities in a new paradigm, it is possible to move from traditional insurance products to new ones, which in turn will become the basis for regional development. Based on the analysis of the current state of the insurance market, the authors have concluded that insurance products/services need to be continuously improved, which will allow insurance companies to increase the flow of insured, to maximize the financial results of insurance companies.
\end{abstract}

\section{Introduction}

The pandemic has forced many to rethink their views on life, the economy and protecting their financial well-being. The negative effects from the 2020 crisis highlight the need for a protection means such as insurance. Through the development of existing and the introduction of innovative features, insurance companies will be able to grow steadily. This, in turn, will enable them to expand their line of insurance products and minimise various risks, including the social and financial risks of the population.

Based on the above, we conclude that it is relevant and necessary to consider innovative opportunities for insurance development in the new paradigm as a tool for increasing financial sustainability in the Russian economy and reducing the risks of loss or minimisation of insurers' profits.

There is currently no consensus on what the innovation is. In our view, this is the reason why it is difficult to understand the concept from the perspective of different scientific fields. We will define innovation as the creative and commercial components of the organisation's activities that are in demand. The creative component includes the creation and use of new technologies that are in demand, the development of Internet insurance, for example, the issuing and selling of digital insurance policies, the development of IT

\footnotetext{
* Corresponding author: mano_86arm@mail.ru
} 
systems that have contributed to the development of new insurance risks, and the use of artificial intelligence.

The commercial component includes the creation of new insurance products/services to expand the insurer's share of the insurance market.

The use of artificial intelligence will minimise service time for the insurance customer and settle claims more quickly. At present, the insurer's dissatisfaction with untimely and slow service can be changed by artificial intelligence, which will minimise the human factor and reduce the time it takes to make a decision on an insurance claim.

Even a small shift towards automation in insurance will lead to significant savings in time and money. Abroad, insurance companies that use artificial intelligence are much quicker to process insurer's claims and calculate the cost of insurance.

Insurance risks are still a serious growth point. The pandemic, the numerous bankruptcies of insurance companies and the huge number of unemployed people have definitely spurred interest in insurance products/services on the part of individuals and companies. This is especially true for life and health insurance products. In the not too distant future, the 2020 pandemic will bring positive changes for insurance. A case in point is the pandemic that was in the US at the beginning of the twentieth century, the "Spanish Pandemic". Insurance companies suffered financial losses because of the high flow of claims. Between 1918 and 1919 over \$125 million was paid out in claims arising out of the epidemic. This corresponded to half of all life insurance claims. In the aftermath of this adverse effect, there was a reversal of the pandemic effect - new protective insurance products emerged at the time, which had the effect of increasing insurance premiums by $21 \%$ in 1919 and by $16 \%$ in 1920 .

In research studies such scientists as Zhilkina A.N. [1], Klyotskin A.N. [2], Kurgin E.A. [3], Melnik N.A. [4], Savina N.E. [5], Platonov Y.A. [6], and others put the main emphasis on innovativeness of insurance activity.

As a result of the analysis, the following characteristics of the innovative process should be highlighted:

1) a targeted chain of interrelated events for the creation and implementation of innovative insurance products/services,

2) the result of the innovative process is the final insurance product/service,

3) the insurance product/service continues to improve after its creation and implementation,

4) the insurance company receives the maximum economic effect (increase in financial indicators) from the implementation of the innovative insurance product/service.

Thus, in insurance, innovative opportunity through the prism of the innovative process is the interaction of different innovative processes in order to introduce new ideas and products.

The aim of the study is to consider the existing innovative opportunities for insurance development in a new financial paradigm.

\section{Methods}

The following methods were used to consider the innovative opportunities in insurance:

1. Analysis of the current insurance market and the impact of the pandemic on its development;

2. Systematic assessment of innovative processes and innovative opportunities to improve the domestic insurance industry on the basis of its current state;

3. Analysis and choice of alternatives as a compilation of several options for the development of insurance company innovation activities, which will allow insurance 
companies to respond quickly to changes in the external and internal economic and social environment.

\section{Analysis of innovative insurance opportunities}

There are a number of peculiarities in the current practice of insurance protection in Russia that have a negative impact on the development of innovative activity and the introduction of innovative insurance products. Examples of such peculiarities are the complexity of the insurance reserves investment mechanism, illiterate management, low professionalism of human resources, etc.

In our view, innovative opportunities are a combination of the use of existing and the development of new scientific, technological, investment resources, which together contribute to a steady increase in financial performance and allow insurance companies to compete both domestically and internationally.

If the innovative product is properly implemented, insurance or its reorientation towards innovative development will become a source of investment, serving as a guarantee of a quick return on premiums when an insured event occurs. Innovative development will make it possible to make the right choice about investing "temporarily free funds of the investment fund and insurance companies' own funds in physical assets (innovative infrastructure business projects), from which the insurance company will receive more income than from investments in financial assets (deposits in banks, deposits in securities, etc.)" [7].

The coronavirus has affected both households, businesses and the insurance industry. The crisis caused by the unexpected Covid-19 played a dual role, highlighting the problems the industry had faced before.

An analysis of Rosstat's indicators shows that there are 48,070 households in the Russian Federation in 2019. According to the results of the first quarter of 2019, the average cash income per household member was 23,276.41 rubles. "Household consumption expenditure averaged 13,658.5 rubles per household member per month, in urban areas $-14,266.00$ rubles, in rural areas - 12,395.40 rubles. An average of 4,359.6 rubles per person a month is spent on foodstuffs for home consumption; in urban areas, the expenditure is 4,650.5 rubles, in rural areas it is 3,754.9 rubles. The most expensive items in the cost structure for purchase of foodstuffs for home consumption in households living in urban areas were expenses for meat and meat products, milk and dairy products $(17.7 \%)$. In rural households, these items account for $20.2 \%$ and $21.1 \%$, respectively" [8].

Throughout 2019, there has been a low growth in expenditure, with the main item of household expenditure being on food and basic necessities. Savings of household members also declined in 2019. The introduction of self-isolation has also had an impact on the reduction in travel area.

According to Expert RA rating agency, insurance market indicators for the first 6 months of 2020 remained at the same level as for the same period in 2019. The volume of premiums collected amounted to 739 billion rubles. Considering the non-life (non-life insurance) market in absolute terms, it increased to 560 billion rubles. The life insurance market declined by $2.5 \%$ and stood at 179 billion rubles. 


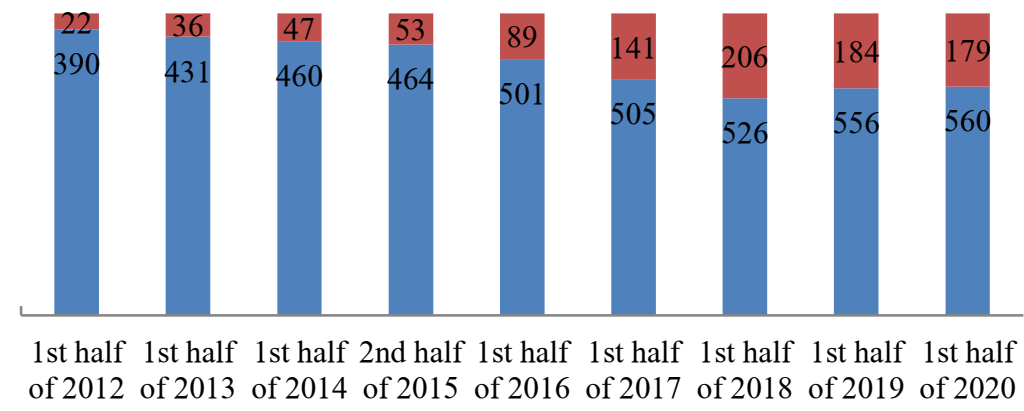

- life insurance premiums, in billion rubles

Fig. 1. Insurance market dynamics over the period 2012-2020 (Expert RA, 2020)

The analysis of the six largest types of insurance shows a negative trend in the second quarter of 2020. Compared to the first quarter of 2019, the growth rate of non-life insurance premiums increased by $11.6 \%$. Compared to the first half of 2019 , there was a slight positive trend in VHI premiums by 1.2 billion rubles. Accident and sickness insurance, motor hull insurance and financial risk insurance were the most affected by the pandemic: RUB -2.8 billion rubles, -2.7 billion rubles and 5.4 billion rubles respectively.

Insurers lost entirely one of their most important revenue sources - overseas travel insurance - and were faced with a large number of returns on "travel" services. Market players who specialised in this type of insurance were particularly affected. Thanks to the research of A.M. Best [a rating agency which, unlike Standard \& Poor's, Moody's and Fitch Ratings, works for a wide business sector and historically has focused exclusively on the insurance market (insurance companies)] who surveyed 450 insurers from 48 countries, "almost $90 \%$ of insurers hope that innovation can help them deal with system failures and $63 \%$ believe that ongoing investment in innovation can help them overcome business disruption and remain on track" [9].

Numerous bankruptcies, declining incomes, rising unemployment and a self-isolation regime have significantly affected the growing interest in insurance products by households, in particular in life and health insurance services. The pandemic and the prolonged "mask crisis" of 2020 will contribute to a positive trend in insurance performance, especially if insurance companies move towards innovative development.

According to a study by RA A.M. Best, more than half of the insurers surveyed "allocated between 1 and $5 \%$ of their budgets to innovation, while $17 \%$ of insurers allocated more than 5\%" [9].

Thanks to cloud computing, blockchain technology and artificial intelligence, the insurance industry's value chain can be transformed. "According to analysts, the total blockchain technology market in the insurance market will grow from $\$ 64.5$ million in 2018 to $\$ 1,393.8$ billion by 2023 at a compound annual growth rate (CAGR) of $84.9 \%$. The global blockchain market is projected to grow at an average CAGR of $80.2 \%$ over the same time period. Factors such as the growing number of fraudulent insurance claims and the growing need for transparent and reliable systems will contribute to the growth of the global technology market" [10].

More than $70 \%$ of the insurance market believes that the improvement of existing and the use of new digital technologies will increase the competitiveness of insurance companies and influence the diversification of the insurance portfolio.

It is artificial intelligence that has enormous potential to help automate virtually all insurance processes, which will minimise the time it takes to process insurance coverage, 
improve the quality of service for potential customers, and allow for a faster claims handling process. In this way, potential customers who decide to use the services of an insurance company will be able to save their time and budget.

The rapid action of artificial intelligence in analysing the data required to conclude an insurance contract will enable insurers and households to better understand the nature of the risks of an insured event, so that risks can be minimised and a new insurance solution can be developed on this basis. The innovative application and development of IT systems will enable insurers to identify and prevent risks in real time.

While the domestic insurance market lags behind the banking industry in terms of technology and innovation, it is in a special position to apply blockchain technology. This technology will be a competitive advantage in the insurance industry by helping many insurers to increase households' interest in insurance services. There are three necessary criteria for development:

1. Ensuring an increase in insurance premiums,

2. Increasing the efficiency of insurance activities,

3. Minimising costs by automating key processes.

By using blockchain technology, insurance companies will be able to:

1. improve the interest of households,

2. offer a cost-effective and innovative product for emerging markets, which becomes particularly relevant in the context of pandemic conditions,

3. develop a set of innovative insurance services that are linked to the Internet of Things.

One of the basic conditions for the use of insurance protection is its affordability. Consequently, insurance companies should conduct a market analysis before creating an innovative product to determine the need for it and the possibility for the public to purchase it.

\section{Conclusions and Recommendations}

By analysing the innovative development of the insurance sector, the following conclusions and recommendations have been drawn:

1. innovative opportunities include the process of introducing new (innovative) insurance products/services

2. Increasing the level of innovative capacity of insurance companies' staff will improve the innovative development of the organisation

3. rapid action of artificial intelligence in the analysis of data required to conclude an insurance contract will allow insurers and households to better understand the nature of the risks of insured events

4. There is a tendency for insurers to change their focus from products that provided a temporary competitive advantage to more innovative opportunities aimed at developing remote services for insurers.

\section{References}

1. A.N. Zhilkina, Innovative approach in insurance business management: monograph, 126 (2014)

2. A.N. Klyotskin, Improving Insurance of Innovative Product (2009)

3. E.A. Kurgin, Insurance management: managing the activities of an insurance company, 18 (2005)

4. N.A. Melnik, Scientific Bulletin: Finance, Banks, Investments, 2(47) (2019) 
5. N.E. Savina, Bulletin of the Financial University, 74 (2014)

6. Y.A. Platonov, Innovative development of insurance activity in modern Russia, 21 (2007)

7. M.A. Mheryan, Insurance Business, 2, 29 (2007)

8. Household income and expenditure for the first quarter of 2019, https://irbis.amursu.ru/

9. Blockchain in insurance: foreign experience and opportunities for Russia, https://ict.moscow/

10. N. I. Lomakin, S. P. Sazonov, O. O. Drobotova, G. I. Lukyanov, O. N. Maximova, G. V. Fedotova, A. V. Petrukhin, A. V. Shokhnekh, R. E. Zvezdin, E. V. Goncharova, MPC null AI-model of financial risk insurance with artificial options (2019) 